\title{
Phytochemicals: Extraction, Isolation, and Identification of Bioactive Compounds from Plant Extracts
}

\author{
Ammar Altemimi ${ }^{1, *}$, Naoufal Lakhssassi ${ }^{2}$, Azam Baharlouei ${ }^{2}$, Dennis G. Watson ${ }^{2}$ \\ and David A. Lightfoot ${ }^{2}$ \\ 1 Department of Food Science, College of Agriculture, University of Al-Basrah, Basrah 61004, Iraq \\ 2 Department of Plant, Soil and Agricultural Systems, Plant Biotechnology and Genome Core-Facility, \\ Southern Illinois University at Carbondale, Carbondale, IL 62901, USA; naoufal.lakhssassi@siu.edu (N.L.); \\ baharlouei@siu.edu (A.B.); dwatson@siu.edu (D.G.W.); ga4082@siu.edu (D.A.L.) \\ * Correspondence: ammaragr@siu.edu; Tel.: +964-773-564-0090
}

Academic Editor: Ulrike Mathesius

Received: 19 July 2017; Accepted: 19 September 2017; Published: 22 September 2017

\begin{abstract}
There are concerns about using synthetic phenolic antioxidants such as butylated hydroxytoluene (BHT) and butylated hydroxyanisole (BHA) as food additives because of the reported negative effects on human health. Thus, a replacement of these synthetics by antioxidant extractions from various foods has been proposed. More than 8000 different phenolic compounds have been characterized; fruits and vegetables are the prime sources of natural antioxidants. In order to extract, measure, and identify bioactive compounds from a wide variety of fruits and vegetables, researchers use multiple techniques and methods. This review includes a brief description of a wide range of different assays. The antioxidant, antimicrobial, and anticancer properties of phenolic natural products from fruits and vegetables are also discussed.
\end{abstract}

Keywords: antimicrobial; antioxidants; medicinal plants; BHT

\section{Introduction}

Many antioxidant compounds can be found in fruits and vegetables including phenolics, carotenoids, anthocyanins, and tocopherols [1]. Approximately 20\% of known plants have been used in pharmaceutical studies, impacting the healthcare system in positive ways such as treating cancer and harmful diseases [2]. Plants are able to produce a large number of diverse bioactive compounds. High concentrations of phytochemicals, which may protect against free radical damage, accumulate in fruits and vegetables [3]. Plants containing beneficial phytochemicals may supplement the needs of the human body by acting as natural antioxidants [4]. Various studies have shown that many plants are rich source of antioxidants. For instance, vitamins A, C, E, and phenolic compounds such as flavonoids, tannins, and lignins, found in plants, all act as antioxidants [3]. The consumption of fruits and vegetables has been linked with several health benefits, a result of medicinal properties and high nutritional value [5]. Antioxidants control and reduce the oxidative damage in foods by delaying or inhibiting oxidation caused by reactive oxygen species (ROS), ultimately increasing the shelf-life and quality of these foods [6]. Beta carotene, ascorbic acid, and many phenolics play dynamic roles in delaying aging, reducing inflammation, and preventing certain cancers [7]. Increasing the consumption of fruits and vegetables has been recommended by many agencies and health care systems throughout the world [8].

The objective of this paper is to provide a review of phytochemical studies that have addressed extracting, measuring and identifying bioactive compounds of plants. This review includes an overview 
of the lipid oxidation process, details of plants known to be antioxidant and antimicrobial sources, phenolic compounds, antioxidants from vegetables and fruits, cancer prevention, extraction techniques for phenolic compounds, isolation and purification of bioactive molecules, and techniques for structural classification of bioactive molecules.

\section{Methods Used for Bioactive Compound Extraction, Isolation, and Purification}

\subsection{Extraction of Phenolic Compounds Using Solvents}

Scientists have studied and analyzed the impact of different types of solvents, such as methanol, hexane, and ethyl alcohol, for the purpose of antioxidant extraction from various plants parts, such as leaves and seeds. In order to extract different phenolic compounds from plants with a high degree of accuracy, various solvents of differing polarities must be used [9]. Moreover, scientists have discovered that highly polar solvents, such as methanol, have a high effectiveness as antioxidants.

Anokwuru et al. reported that acetone and $N, N$ dimethylformamide (DMF) are highly effective at extracting antioxidants, while Koffi et al. found that methanol was more effective in at a large amount of phenolic contents from walnut fruits when compared to ethanol [10-12].

It has been reported that ethanolic extracts of Ivorian plants extracted higher concentrations/amount of phenolics compared to acetone, water, and methanol [11]. Multiple solvents have been commonly used to extract phytochemicals, and scientists usually employed a dried powder of plants to extract bioactive compounds and eliminate the interference of water at the same time.

Solvents used for the extraction of biomolecules from plants are chosen based on the polarity of the solute of interest. A solvent of similar polarity to the solute will properly dissolve the solute. Multiple solvents can be used sequentially in order to limit the amount of analogous compounds in the desired yield. The polarity, from least polar to most polar, of a few common solvents is as follows: Hexane $<$ Chloroform $<$ Ethylacetate $<$ Acetone $<$ Methanol $<$ Water.

\subsection{Microwave-Assisted Extraction (MAE)}

MAE has attracted the attention of researchers as a technique to extract bioactive compounds from a wide variety of plants and natural residues [12]. Microwaves have electromagnectic radiation that occurs at frequencies between $300 \mathrm{MHz}$ to $300 \mathrm{GHz}$, and wavelengths between $1 \mathrm{~cm}$ and $1 \mathrm{~m}$. These electromagnetic waves consist of both an electrical field and a magnetic field. These are described as two perpendicular fields. The first application of microwaves was to heat up objects that can absorb a part of the electromagnetic energy and convert it into heat. Commercial microwave instruments commonly use the frequency $2450 \mathrm{MHz}$, which corresponds to an energy output of 600-700 Watts [13].

Recently, advanced techniques have become available to reduce the loss of bioactive compound without increasing the extraction time. Therefore, microwave-assisted extraction is demonstrated to be a good technique in multiple fields, especially in the medicinal plant area. Moreover, this technique reduced the losses of the biochemical compounds being extracted [14]. Microwave-assisted extraction (MAE) has been used as an alternative to conventional techniques for the extraction of antioxidants because of its ability to reduce both time and extraction solvent volume [15]. In fact, the main objective of using MAE is to heat the solvent and extract antioxidants from plants with a lesser amount of these solvents [13].

Li et al. reported that conventional methods using various solvents presented less antioxidant activity and phenolic content than MAE [16]. Therefore, the finding confirmed that MAE was more effective at increasing antioxidant activity by measuring ferric reducing antioxidant power (FRAP), oxygen radical absorbance capacity (ORAC), and total phenolic content (TPC). The efficiency of the microwave extraction can be changed through some factors such as extraction temperature, solvent composition, and extraction time. The extraction temperature was usually studied more than other factors due to its ability to increase the efficiency of the microwave extraction. Tsubaki et al. reported that $170{ }^{\circ} \mathrm{C}$ was the most effective temperature for extracting phenolic compounds from Chinese tea. In addition, 
increasing the extraction temperature beyond this point resulted in a reduced extraction yield [17]. Recently, Christophoridou et al. used a new microwave-assisted extraction (MAE) process, which converts energy to heat, thereby cooperating with solvents in order to extract a specific compound [18]. Williams et al. showed many advantages of MAE, including lower solvent consumption, shorter extraction times, and higher sensitivity towards target molecules [19]. A comparison of some antioxidant methods used has been provided in Table 1.

Table 1. Comparison of methods for assessing antioxidant capacity based upon mechanism, endpoint, quantitation method, and whether the assay is adaptable to measure lipophilic and hydrophilic antioxidants.

\begin{tabular}{ccccc}
\hline Antioxidant Assay & Mechanism & Endpoint & Quantification & Lipophilic and Hydrophilic AOC \\
\hline ORAC & HAT & Fixed time & AUC & Yes \\
TRAP & HAT & Lag phase & IC50 lag time & No \\
FRAP & SET & Time varies & $\Delta$ OD fixed time & No \\
TEAC & SET & Time varies & $\Delta$ OD fixed time & Yes \\
DPPH & SET & IC50 & $\Delta$ OD fixed time & No \\
LDL oxidation & SET & Lag phase & Lag time & No \\
\hline
\end{tabular}

\subsection{Ultrasonic-Assisted Extraction}

Ultrasound-assisted extraction (UAE) has been used in diverse applications of food-processing technology to extract bioactive compounds from plant materials [19]. Ultrasound, with levels greater than $20 \mathrm{kHz}$, is used to disrupt plant cell walls, which helps improve the solvent's ability to penetrate the cells and obtain a higher extraction yield. UAE can use a low operating temperature through processing, maintaining a high extract quality for compounds. UAE is known to be one of the easiest extraction techniques because it uses common laboratory equipment such as an ultrasonic bath. In this technique, a smashed sample is mixed with the suitable solvent and placed into the ultrasonic bath, while temperature and extraction time are controlled [20].

UAE of various organic and inorganic samples can use a wide range of solvents. Common equipment used in ultrasound-assisted extraction includes an ultrasonic bath and an ultrasonic probe system. Unfortunately, ultrasonic probe has two main negative properties mainly related to experimental repeatability and reproducibility [21].

Tabaraki et al. noted that green technology is necessary to protect the environment from toxic substances [22]. Therefore, extraction of phenolic compounds by ultrasound has grown during recent years due to its role in reducing the amount of solvent and energy used. Corrales et al. have shown that UAE can break down plant tissue and work properly during the production process and release of active compounds in solvents with a high efficiency [21]. Results showed an increase in antioxidant activity from $187.13 \mu \mathrm{mol} \mathrm{TE} \mathrm{g}^{-1} \mathrm{DM}$ to $308 \mu \mathrm{mol} \mathrm{TE} \mathrm{g}^{-1} \mathrm{DM}$ by using UAE as an effective method to extract antioxidants from different sources. Recently, Albu et al. studied and applied the use of ultrasound to extract phenolic compounds from rosemary [23]. Multiple criteria have been compared including ultrasonic bath extractions, ultrasonic probe system, a shaking water bath at various temperatures, and different solvents to select the most efficient method. In all situations, the operation time was dramatically decreased by applying and using the ultrasonic bath and probe systems.

Similar behavior was reported by Cho et al. when extracting resveratrol from grapes [24]. In another study, Barbero et al. suggested the use of ultrasound in different industries because of its positive effects in the extraction of capsaicinoids of hot peppers [25]. Moreover, the ultrasonic method had the ability to decrease the degradation of phenolics [26]. Mulinacci et al. compared the extraction time of phenolic compounds from strawberries with other extraction methods such as solid-liquid, subcritical water, and microwave-assisted method [27]. The results confirmed that UAE was the most effective method. 


\subsection{Techniques of Isolation and Purification of Bioactive Molecules from Plants}

Purification and isolation of bioactive compounds from plants is a technique that has undergone new development in recent years $[28,29]$. This modern technique offers the ability to parallel the development and availability of many advanced bioassays on the one hand, and provided precise techniques of isolation, separation, and purification on the other. The goal when searching for bioactive compounds is to find an appropriate method that can screen the source material for bioactivity such as antioxidant, antibacterial, or cytotoxicity, combined with simplicity, specificity, and speed [27].

In vitro methods are usually more desirable than in vivo assays because animal experiments are expensive, take more time, and are prone to ethical controversies. There are some factors that make it impossible to find final procedures or protocols to isolate and characterize certain bioactive molecules. This could be due to different parts (tissues) in a plant, many of which will produce quite different compounds, in addition to the diverse chemical structures and physicochemical properties of the bioactive phytochemicals [30]. Both the selection and the collection of plant materials are considered primary steps to isolate and characterize a bioactive phytochemical. The next step involves a retrieval of ethno-botanical information to discern possible bioactive molecules. Extracts can then be made with various solvents to isolate and purify the active compounds that are responsible for the bioactivity. Column chromatographic techniques can be used for the isolation and purification of the bioactive compounds. Developed instruments such as High Pressure Liquid Chromatography (HPLC) accelerate the process of purification of the bioactive molecule. Different varieties of spectroscopic techniques like UV-visible, Infrared (IR), Nuclear Magnetic Resonance (NMR), and mass spectroscopy can identify the purified compounds [31].

\subsection{Purification of the Bioactive Molecule}

Many bioactive molecules have been isolated and purified by using paper thin-layer and column chromatographic methods. Column chromatography and thin-layer chromatography (TLC) are still mostly used due to their convenience, economy, and availability in various stationary phases [32]. Silica, alumina, cellulose, and polyamide exhibit the most value for separating the phytochemicals. Plant materials include high amounts of complex phytochemicals, which make a good separation difficult [32]. Therefore, increasing polarity using multiple mobile phases is useful for highly valued separations. Thin-layer chromatography has always been used to analyze the fractions of compounds by column chromatography. Silica gel column chromatography and thin-layer chromatography (TLC) have been used for separation of bioactive molecules with some analytical tools [32].

\subsection{Structural Clarification of the Bioactive Molecules}

Determination of the structure of certain molecules uses data from a wide range of spectroscopic techniques such as UV-visible, Infrared (IR), Nuclear Magnetic Resonance (NMR), and mass spectroscopy. The basic principle of spectroscopy is passing electromagnetic radiation through an organic molecule that absorbs some of the radiation, but not all. By measuring the amount of absorption of electromagnetic radiation, a spectrum can be produced. The spectra are specific to certain bonds in a molecule. Depending on these spectra, the structure of the organic molecule can be identified. Scientists mainly use spectra produced from either three or four regions-Ultraviolet (UV), Visible, Infrared (IR), radio frequency, and electron beam [31]—for structural clarification.

\subsection{UV-Visible Spectroscopy}

UV-visible spectroscopy can be performed for qualitative analysis and for identification of certain classes of compounds in both pure and biological mixtures. Preferentially, UV-visible spectroscopy can be used for quantitative analysis because aromatic molecules are powerful chromophores in the UV range. Natural compounds can be determined by using UV-visible spectroscopy [33]. Phenolic compounds including anthocyanins, tannins, polymer dyes, and phenols form complexes with iron 
that have been detected by the ultraviolet/visible (UV-Vis) spectroscopy [34]. Moreover, spectroscopic UV-Vis techniques were found to be less selective and give information on the composition of the total polyphenol content. The UV-Vis spectroscopy was used to determine the total phenolic extract $(280 \mathrm{~nm})$, flavones $(320 \mathrm{~nm})$, phenolic acids $(360 \mathrm{~nm})$, and the total anthokyanids $(520 \mathrm{~nm})$. This technique is not time-consuming, and presents reduced cost compared to other techniques [35].

\subsection{Infrared Spectroscopy}

Some of the frequencies will be absorbed when infrared light passes through a sample of an organic compound; however, some frequencies will be transmitted through the sample without any absorption occurring. Infrared absorption is related to the vibrational changes that happen inside a molecule when it is exposed to infrared radiation. Therefore, infrared spectroscopy can essentially be described as a vibrational spectroscopy. Different bonds $(\mathrm{C}-\mathrm{C}, \mathrm{C}=\mathrm{C}, \mathrm{C} \equiv \mathrm{C}, \mathrm{C}-\mathrm{O}, \mathrm{C}=\mathrm{O}, \mathrm{O}-\mathrm{H}$, and $\mathrm{N}-\mathrm{H})$ have diverse vibrational frequencies. If these kinds of bonds are present in an organic molecule, they can be identified by detecting the characteristic frequency absorption band in the infrared spectrum [35]. Fourier Transform Infrared Spectroscopy (FTIR) is a high-resolution analytical tool to identify the chemical constituents and elucidate the structural compounds. FTIR offers a rapid and nondestructive investigation to fingerprint herbal extracts or powders.

\subsection{Nuclear Magnetic Resonance Spectroscopy (NMR)}

NMR is primarily related to the magnetic properties of certain atomic nuclei; notably the nucleus of the hydrogen atom, the proton, the carbon, and an isotope of carbon. NMR spectroscopy has enabled many researchers to study molecules by recording the differences between the various magnetic nuclei, and thereby giving a clear picture of what the positions of these nuclei are in the molecule. Moreover, it will demonstrate which atoms are present in neighboring groups. Ultimately, it can conclude how many atoms are present in each of these environments [33]. Several attempts have been made in the past by using preparative or semi preparative thin-layer chromatography, liquid chromatography, and column chromatography to isolate individual phenols, the structures of which are determined subsequently by NMR off-line [34].

\subsection{Mass Spectrometry for Chemical Compounds Identification}

Organic molecules are bombarded with either electrons or lasers in mass spectrometry and thereby converted to charged ions, which are highly energetic. A mass spectrum is a plot of the relative abundance of a fragmented ion against the ratio of mass/charge of these ions. Using mass spectrometry, relative molecular mass (molecular weight) can be determined with high accuracy and an exact molecular formula can be determined with a knowledge of places where the molecule has been fragmented [18]. In previous work, bioactive molecules from pith were isolated and purified by bioactivity-guided solvent extraction, column chromatography, and HPLC [36]. The techniques of UV-visible, IR, NMR, and mass spectroscopy were employed to characterize the structure of the bioactive molecule. Furthermore, molecules may be hydrolyzed and their derivatives characterized. Mass spectrometry provides abundant information for the structural elucidation of the compounds when tandem mass spectrometry (MS) is applied. Therefore, the combination of HPLC and MS facilitates rapid and accurate identification of chemical compounds in medicinal herbs, especially when a pure standard is unavailable [37-40]. Recently, LC/MS has been extensively used for the analysis of phenolic compounds. Electrospray ionization (ESI) is a preferred source due to its high ionization efficiency for phenolic compounds.

\section{Lipid Oxidation}

Lipid oxidation can occur during the processing, shipping, and storing of many foods. Lipids (such as triglycerides, sterols, and phospholipids) readily become oxidized with exposure to an oxidative environment [41]. Lipid molecules, especially those carrying polyunsaturated double 
bonds (i.e., linolenic acids), readily undergo oxidation within foods. Oxidatively stable oil with high melting temperature is necessary for solid fat application, and thus, highly saturated seed oil (palmitic acid and stearic acid) would be suitable for this end use [42]. Soybeans provide $56 \%$ of the world's oilseed production. However, the percentage of saturated oil is very low in seed plants (about 10\%), if compared to unsaturated oil (about 90\%) [43]. Palmitic acid improves the oxidative stability of soybean oil, and can also be used to produce trans-fat-free shortening, margarine, and cosmetic products. However, this saturated short-chain fatty acid is undesirable for nutrition because its consumption results in an unfavorable lipoprotein profile in blood serum [44]. Stearic acid does not exhibit these cholesterolemic effects on human health [45]. Stearic acid is less likely to be incorporated into cholesterol esters and has a neutral effect on the concentration of blood serum LDL cholesterol [46,47]. Extensive research has been performed in order to increase stearic acid content oil production in the most widely consumed legume crop in the world, soybeans. By employing induced mutagenesis, seed stearic acid content was increased by up to 7 times [48].

Lipid oxidation in food systems can be caused by oxygen free radicals or reactive oxygen species. Free radicals are molecules with one or more unpaired electrons that work independently to cause oxidation [49]. Reactive oxygen species are a perfect example of oxygen free radicals. Reactive oxygen species do not solely contain free radical molecules, but also some non-free radicals that can influence lipid oxidation. Examples of non-free radical reactive oxygen species are hydrogen peroxide $\left(\mathrm{H}_{2} \mathrm{O}_{2}\right)$, hydrochloric acid $(\mathrm{HCl})$, ozone $\left(\mathrm{O}_{3}\right)$, and molecular oxygen $\left(\mathrm{O}_{2}\right)$ [42]. Molecular oxygen can react with linoleic acid about 1450 times faster than triplet oxygen. One of the major causes of oil rancidity is molecular oxygen. Lipid oxidation caused by the chain reaction of free radicals can be illustrated in three stages: initiation, propagation, and termination [42]:

(1) Initiation:

$$
\begin{aligned}
& \mathrm{RH}+\text { initiator } \rightarrow \mathrm{R} \\
& \mathrm{ROOH}+\text { initiator } \rightarrow \mathrm{ROO} \bullet
\end{aligned}
$$

(2) Propagation:

$$
\begin{aligned}
& \mathrm{R}+\mathrm{O}_{2} \rightarrow \mathrm{ROO} \\
& \mathrm{ROO}+\mathrm{RH} \rightarrow \mathrm{ROOH}+\mathrm{R} \bullet
\end{aligned}
$$

(3) Termination:

$$
\begin{aligned}
& \mathrm{R}+\mathrm{R} \rightarrow \mathrm{R}-\mathrm{R} \\
& \mathrm{ROO} \bullet+\mathrm{R} \rightarrow \mathrm{ROOH}
\end{aligned}
$$

The processes above occur in response to several physical or chemical factors including heating, radiation, temperature, metal ion catalysts, reactive oxygen species, and photosensitizers such as chlorophyll. The initiation step, shown in Equation (1), often happens at either an allytic methylene group of an unsaturated fatty acid $(\mathrm{RH})$ or a lipid-hydroperoxide $(\mathrm{ROOH})$. Next, the generated free radical $(\mathrm{R} \bullet)$ reacts with oxygen to form a peroxy radical $(\mathrm{ROO} \bullet)$. This product can directly react with

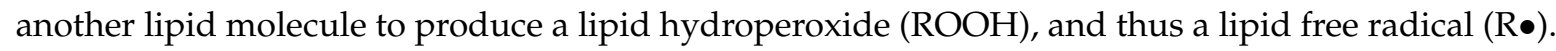
This causes continuously cascading chain reactions to occur until the free radicals are neutralized by other free radicals. This whole stage is shown in Equation (2). In the termination step, there are two radicals that have converted into non-free radical products, and thus will stop the cascade mode of the chain reaction according to Equation (3). Moreover, the reaction chain can also be terminated by some antioxidants or free radical scavengers. Metal ions, especially those of iron and copper, effectively catalyze these reactions [50].

Lipoxygenases (EC 1.13.11) can also act, causing oxidation to produce the peroxides in food materials that contain lipids. Hydrogen peroxide is one of the primary products of the oxidation, and it is very unstable and easily converts into secondary products. The final product of oxidation may 
include different chemical groups such as aldehydes, ketones, alcohols, acids, or hydrocarbons. These kinds of compounds can have a negative effect on the appearance, quality, and edibility of a food product by changing the texture, color, flavor, and safety of foods, or also by producing unacceptable off odors or off tastes, even negatively affecting the nutritional value [50].

\section{Plants as a Source of Antioxidants}

Antioxidants can be defined as bioactive compounds that inhibit or delay the oxidation of molecules [42]. Antioxidants are categorized as natural or synthetic antioxidants. Some synthetic antioxidants commonly used are: BHT, BHA, propyl gallate, and tertbutylhydroquinine. Many scientists have concerns about safety because synthetic antioxidants have recently been shown to cause health problems such as liver damage, due to their toxicity and carcinogenicity. Therefore, the development of safer antioxidants from natural sources has increased, and plants have been used as a good source of traditional medicines to treat different diseases. Many of these medicinal plants are indeed good sources of phytochemicals that possess antioxidant activities. Some typical examples of common ingredients that have been used in ethnic foods are tamarind, cardamom, lemon grass, and galangal basil. These spices or herbs have been shown to contain antioxidants [51].

Deterioration of food due to either bacterial or fungal infection has always been a major concern, causing huge losses to food industries and societies throughout the world [51]. Moreover, the spread of food pathogens has become a major public health concern. With an increasing awareness of the negative effects of synthetic preservatives, there has been increased demand for the use of nontoxic, natural preservatives, many of which are likely to have either antioxidant or antimicrobial activities [52,53]. Herbs have always been used for flavor and fragrance in the food industry, and some of them have been found to exhibit antimicrobial properties [54]. Therefore, the call for screening and using plant materials for their antioxidant and antimicrobial properties has increased. Approximately $20 \%$ of all plant species have been tested in both pharmacological and biological applications to confirm their safety and advantages [3]. A summary of the types of compounds, plant species, plant parts from which compounds were extracted, etc. can be found in Table S1.

\subsection{Presence of Antioxidant in Red Algae}

Red algae are aquatic plant species considered one of the oldest groups of eukaryotic algae [55]. The antioxidant activity of a red alga, Palmaria palmate, has been studied. The results reported that $9.68 \mu \mathrm{g}$ of ascorbic acid and $10.3 \mu \mathrm{g}$ of total polyphenol can equally reduce activity in $1 \mathrm{mg}$ of dulse extracts. The reducing activity was correlated with aqueous/alcohol soluble compounds due to the presence of functional groups such as hydroxyl, carbonyl, etc., which lead to reduced or inhibited oxidation [56].

\subsection{Antioxidants from Monocots}

Ashawat et al. studied the antioxidant properties of ethanolic extracts of Areca catechu and showed that Areca catech $u$ had the highest antioxidant activity when compared to other eudicots like Centella asiatica, Punica granatum, and Glycyrrhiza glabra [57]. Londonkar and kamble studied Pandanus odoratissimus L. in order to determine its antioxidant activity [58]. Zahin et al. screened Acorus calamus to estimate antioxidant activity and total phenolic contents [59]. The observations confirmed that there was a significant correlation between the phenolic content and antioxidant activity. Another monocot, O. sanctum, showed that the inhibition of lipid peroxidation in vivo and in vitro increased proportionally with an increase in the concentration of the extract.

\subsection{Antioxidants from Vegetables}

Consumption of vegetables has been linked to a reduction in the risk of many diseases, such as cancer and cardiovascular disease, when studied in epidemiological studies [59]. Numerous studies have attempted to screen vegetables for antioxidant activity by using different oxidation systems. 
These vegetables include carrots, potatoes, sweet potatoes, red beets, cabbage, Brussels sprouts, broccoli, lettuce, spinach, onions, and tomatoes. In addition to the concise studies, which have used different methodologies to release bioactive compounds, it is becoming increasingly difficult to ignore advanced extraction methods, which have paved the way to extract bioactive compounds rapidly. Despite scientists' successes in showing the activity of vegetables' bioactive compounds, there is little known about the activity of the antioxidant components that have been isolated from these vegetables. Researchers have tended to focus on advanced methods to isolate and measure the activity of antioxidant compounds such as flavonoids, phenolic acids, tocopherols, carotenoids, and ascorbic acid [60].

\subsection{Antioxidants from Fruits}

Fruit consumption has also been linked to a reduction in the risk of many diseases [61]. Peaches (Prunus persica L.) are an economically important fruit in many countries. Studies have shown that phenolic compounds found within various peach genotypes are a major source of potential antioxidants [60]. Interestingly, peaches have shown a great inhibition of low density lipoprotein (LDL) oxidation with a percentage of antioxidant activity of $56-87 \%$. This antioxidant activity can be attributed to its essential compound content including hydroxycinnamic acids, chlorogenic, and neochlorogenic acids, but not to carotenoids such as b-carotene and b-cryptoxanthin. Moreover, low antioxidant activity was found in peach peel. In contrast, Plumb et al. pointed out that hydroxycinnamic acids do not contribute to the inhibition of lipid peroxidation of the liver using plums and peaches because hydroxycinnamic acids had weak ability to scavenge hydroxyl radicals [62].

Grape (Vitis vinifera L.) is a fruit crop grown throughout the world. Grapes and its juices have been recently studied by [62]. Phenolic compounds were high in both fresh grapes and commercial grape juices. The percentage of inhibition LDL oxidation was about $22 \%$ to $60 \%$ for fresh grapes, while it was approximately $68 \%$ to $75 \%$ for commercial grape juices, when standardized at $10 \mathrm{mg}$ gallic acid equivalents (GAE). According to [63], both grapes and its juices exhibited high oxygen radical absorbance capacity (ORAC), and the anthocyanin pigment malvidin-3,5-diglucoside was a major compound isolated in grapes. Anthocyanins with malvidin nucleus malvidin 3-O-(6-O-p-coumaroylglucosido)-5-glucoside and phenolics were common compounds isolated from wild grapes (Vitis coignetiae). Wangensteen et al. tested the activity of many bioactive compounds by releasing them from grape pomace, and demonstrated that bioactive compounds have the ability to significantly inhibit LDL oxidation in the human body [64]. Grape seeds are an amazing source of polyphenol compounds including monomerics such as catechin, epicatechin, and gallic acid, and polymerics such as procyanidins [65].

Both polyphenols and carotenoids are the major phenolic compounds of apples (Malus domestica L.) including caffeic, quinic, and p-coumaric acids. These polyphenols can act as antioxidants. Flavanol monomers and oligomers, as well as quercetin, contribute to the beneficial health aspects of fruits and vegetables [65]. Apple pomace has mainly been used as a major source of polyphenols such as chlorogenic acid [66,67]. In addition phenolics like caffeic, p-coumaroyl quinic, arbutin, p-coumaric acids, and especially flavonol procyanidins have been mentioned as constituents of apple pomace [68]. The ability of procyanidins to work as oxygen radical scavengers, superoxides, and hydroxyl radicals was estimated. Despite the low content in total phenols in apples obtained by using acetone $70 \%$, it has shown strong antioxidant activities towards oxidation of linoleic acid. In this case, the major bioactive compounds obtained were chlorogenic acid and phloretin glycosides; however, Vitamin $\mathrm{C}$ was a minor fraction in apple juice [69].

Antioxidant and antibacterial activities of various solvent (ethyl acetate, acetone, methanol, and water) extracts of Punica granatum peel were examined by applying the 2,2-diphenyl-1-picrylhydrazyl (DPPH) radical scavenging method. The results obtained showed a significantly higher decreasing power in the methanol extracts and a significantly higher antibacterial activity in the acetone extracts.

Soong and Barlow investigated the antioxidant activity and phenolic content of various fruit seeds [70]. Petroleum ether was used to get rid of the excess fat from the seeds and extraction has been 
carried out with methanol. The 2,2-azino-bis-3-ethylbenzthiazoline-6-sulfonic acid (ABTS), DPPH, and the ferric reducing ability of plasma (FRAP) methods were used to investigate the antioxidant activity. Abdille et al. examined the antioxidant activity of Dillenia indica fruit using different kinds of solvents using DPPH, phospho-molybdenum, and $\beta$ carotene bleaching methods [71]. The methanol extracts showed the highest antioxidant activity, followed by the ethyl acetate and water extracts. Antioxidant activity of Syzygium cumini fruit in vitro has been investigated [71]. Antioxidant activity was measured by DPPH, superoxide, lipid peroxidation, and hydroxyl radical scavenging activity methods. The results brought to light a significant correlation between the concentration of the extract and the percentage of inhibition of free radicals. The antioxidant property of the fruit might be from the presence of antioxidant vitamins, anthocyanins, phenolics, and tannins. It has been reported that blackberry (Rubus fruticosus L.) fruit extracts produced in varying climatic regions showed that antioxidant activity depended on the genotype, rather than the climate or season [10]. Juntachote and Berghofer measured the stability of the antioxidant activity of ethanolic extracts for Holy basil and galangal using DPPH, superoxide, $\beta$ carotene bleaching, reducing power, and iron chelation methods [72]. They found higher antioxidant activity at neutral $\mathrm{pH}$ compared to an acidic $\mathrm{pH}$. Holy basil and galangal extracts provided strong iron chelation activity, superoxide anion scavenging activity, and reducing power proportional to the concentration of the extracts. Liyana-Pathirana et al. investigated the antioxidant activity of cherry laurel fruit (Laurocerasus officinalis Roem) and its concentrated juice (Pekmez) using in vitro methods such as superoxide, DPPH scavenging activity, and inhibition of LDL oxidation [73]. The results confirmed the presence of a significantly higher antioxidant activity in pekmez compared to the cherry laurel fruit. Employing in vitro methods such as DPPH and superoxide scavenging activity, Orhan et al. measured the antioxidant activity of Arnebia densiflora Ledeb and observed that polar extracts had a higher antioxidant activity compared to non-polar extracts [74]. Rathee et al. studied the antioxidant activity of Mammea longifolia buds extracted in both methanol and aqueous ethanol. The results found a significant antioxidant activity, and the activity of aqueous ethanol was higher than methanol. The antioxidant activity of leaf extracts of Annona species in vitro reveals that Annona muricata possessed a higher antioxidant activity compared to Annona squomosa [75].

\subsection{Cooking Herbs as an Important Source of Antioxidants}

The antioxidant activity of 32 herbs belonging to 21 different families has been screened [76]. The finding confirmed that there was a positive correlation between the total antioxidant activity and total phenolic content. Lu and Yeap Foo studied Salvia officinalis (L.) for its antioxidant activity and polyphenol content and reported that rosmarinic acid and various catechols were responsible for the radical scavenging activity and caffeic acid was responsible for the xanthine oxidase (EC 1.17.3.2) inhibition [77]. Zhao et al. investigated the antioxidant activity of Salvia miltiorrhiza and Panax notogensing [78]. The results showed that Salvia miltiorrhiza had a higher reducing power and scavenging activities against free radicals, including superoxide and hydroxyl radicals, although it showed weak hydrogen peroxide scavenging.

Furthermore, Javanmardi et al. tested the Iranian Ocimum sp. accessions to determine the antioxidant activities and total phenolic contents and demonstrated that the antioxidant activity increased in parallel with the total phenolic content [51].

Evaluation of the pomegranate peel extracts to discover its antioxidant and antimutagenic activities using different solvents such as ethyl acetate, acetone, methanol and water has been carried out [51]. Dried extracts were examined by using the Ames test and the phosphorus-molybdenum method to test both anti-mutagenic and antioxidant activities. The results showed the highest anti-mutagenic and the lowest antioxidant activity in the water extract.

Moreover, the phenolic content and antioxidant activity of parsley (Petroselinum crispum) and cilantro (Coriandrum satioum) have been tested [79]. The total phenolic content was observed to be different between parsley and cilantro leaves and stems, as well as methanol and water extracts. The methanol 
leaf extracts exhibited significant antioxidant activity towards both lipid- and water-soluble radicals. The works also investigated the antioxidant activity of aqueous plant extracts using in vitro methods such as DPPH scavenging activity and FRAP. The results revealed a strong correlation between total antioxidant activity and phenolic content and a weak correlation between cupric ion chelators and polyphenols. The antioxidant activity and lipid peroxidation inhibition of Satureja montana L. subsp. Kitaibelii extracts were tested using hydroxyl radical scavenging. The results obtained showed that there was a significant correlation with total phenolic content [9].

\subsection{Antioxidant from Legumes}

Antioxidant property of methanol extracts of Mucuna pruriens L. (Fabaceae) seed extracts has been investigated in vitro using the DPPH radical scavenging method. The results obtained showed a positive correlation between the antioxidant activity and the total phenolic compounds [80]. Siddhuraju and Manian studied horsegram (Macrotyloma uniflorum Lam.) seeds to measure the antioxidant and free radical scavenging activity [81]. Acetone extracts had a higher activity of about 70\% [81]. Samak et al. studied Wagatea sp. to measure its scavenging activities of superoxide and hydroxyl radicals and showed a high oxidation inhibition because it was rich in both phenolic and flavonoid contents. The authors also reported that bark and leaf extracts of Wagatea sp. exhibited high scavenging action against super radicals [82].

\subsection{Antioxidants from Trees}

Antioxidants from trees have been also measured. Phenolics from almond hulls (Prunus amygdalus L.) and pine sawdust (Pinus pinaster L.) have been extracted employing various methods in order to determine the gram fresh yield of polyphenol compounds and antioxidant activity [83]. The antioxidant activity was measured by the DPPH radical scavenging method. The results showed that ethanol was most appropriate either for phenolics or any bioactive compounds, while methanol was more selective for extracting polyphenolics. The antioxidant activity of juniper (Juniperus communes) fruit extracts has been investigated in vitro [84]. The results confirmed that both water and ethanol extract showed strong antioxidant activity. The concentration of $60 \mu \mathrm{g} / \mathrm{mL}$ of water and ethanol extracts exhibited $84 \%$ and $92 \%$ inhibition, respectively, on the peroxidation of linoleic acid. Ibrahim et al. studied the antioxidant activity of Cupressus sempervirens L., and set up goals to isolate quercetin, rutin, cupress flavone, caffeic acid, and para-coumaric acid. The results showed higher antioxidant activity related to quench DPPH and identified these active compounds successively [85].

Higher values of antioxidant activity have been obtained by using a methanolic solvent to extract the bioactive compounds from Anacardium occidentale, while other solvents like ethyl acetate gave lower values of antioxidant activity [85]. Kaur et al. studied the Chickrassy Chukrasia tabularis A. Juss leaves to confirm its ability to inhibit lipid peroxidation and showed that there was a large inhibition considering its high content of phenolic compounds [86]. Finally, Acacia nilotica L. antioxidant activity has been measured using ethyl acetate as a solvent to extract phenolic compounds [86]. The results exhibited the highest antioxidant activity when the concentration of extracts was relatively high.

\subsection{Antioxidant from Shrubs}

Many shrubs have been shown to contain antioxidant activity. Singh et al. tested several plants to measure the antioxidant activity from different extracts. The antioxidant activity was determined by using peroxide value, thiobarbituric acid, DPPH radical scavenging activity, and reducing power. The results showed that the antioxidant activity of Coriandrum sativum L. and Sarcolobus globosus L. exhibited high activity by using acetone solvent, and its activity was similar to synthetic antioxidants [87].

Eleven Algerian medicinal plants have been measured for phenolic compound content and antioxidant activity using the ABTS method. The tested plants showed antioxidant activity. Artemisia campestris L. had better antioxidant activity than caffeic acid and tocopherol. Moreover, 
HPLC analyses exhibited a good correlation between the antioxidant activity and hydroxycinnamic derivative content.

Evaluation of Vitex negundo Linn seed antioxidant activity using different methods such as superoxide, hydroxyl, and DPPH scavenging activity has been carried out [87]. The highest antioxidant activity was in both raw and dry heated seed extracts, while lower antioxidant activity was observed in the hydrothermally processed samples.

\subsection{Characterization of Antioxidants from Other Eudicots}

The nitric oxide and superoxide scavenging activity of green tea have been studied by Nakagawa and Yokozawa [88], who concluded that certain tannins had the ability to exhibit excellent antioxidant activity. Zin et al. estimated the antioxidant activity of the extracts from various parts of Mengkudu (Morinda citrifolia L.), including the leaves, fruits, and roots, using different solvents such as methanol and ethyl acetate [89]. Ferric thiocyanate and thiobarbituric acid were used as models to observe and evaluate the antioxidant activity. The results exhibited a higher antioxidant activity in the methanol extract of Mengkudu root, although it was not significantly different from tocopherol and BHT extracts. The methanol extracts of the fruits and leaves showed unassuming activity. According to these scientists, the antioxidant activity in the roots resulted from polar and non-polar compounds, but the antioxidant activity in leaves and fruits was only due to non-polar compounds.

Increase of the antioxidant activity of fennel (Foeniculum vulgare) seed extracts in vitro has been shown to be proportional to the increase in the concentration of extract [89]. Nine other extracts of Bolivian plants have been measured for radical scavenging and antioxidant activity using the DPPH and $\beta$ carotene bleaching methods [90]. It was found that the ethyl acetate fractions had higher radical scavenging and antioxidant activity compared to the other extracts. It has been reported that the bioactive compounds of Rhodiola rosea extracted in methanol showed a significant yield of phenolics, about (153 $\pm 2 \mathrm{mg} / \mathrm{g})$ [91]. Wangensteen et al. investigated the antioxidant activity of Ss globosus using DPPH scavenging and inhibition of lipoxygenase [64]. Coriander had a high capacity to inhibit oxidation. There was also a positive correlation between total phenolics and antioxidant activity. Moreover, it was observed that the leaves of the coriander had higher antioxidant activity than the seeds [91].

Antioxidant activity of Phyllanthus niruri was estimated using methanol and water as a solvent. The extracts of leaves and fruits exhibited high antioxidant activity by using the inhibition of lipid peroxidation and DPPH scavenging [64]. The results also noticed a higher superoxide scavenging activity in the aqueous extract compared to the methanol extract. Moreover, the antioxidant and free radical scavenging activity of Phyllantus species from India in an aqueous extract has been also evaluated [92]. The antioxidant activity was estimated using DPPH, $\beta$ carotene, superoxide, nitric oxide scavenging, and reducing power methods. The extract of Coleus aromaticus exhibited a moderate inhibition on DPPH and nitric oxide scavenging activity.

Panax exhibited strong iron chelating and weak superoxide scavenging. Ajila et al. carried out bioactive compounds and antioxidant activity of mango peel extract [93]. The results showed a higher concentration of anthocyanins and carotenoids in the ripe peel compared to the raw peel, while the raw peel exhibited higher polyphenol content. The range of IC50 values of lipid peroxidation and DPPH were 1.39-5.24 $\mu \mathrm{g}$ of gallic acid equivalent. Chen and Yen investigated the antioxidant activity and free radical scavenging capacity of dried guava leaves and fruit [94]. The results confirmed that guava leaf and guava tea extracts had the ability to inhibit oxidation by $94-96 \%$ at a concentration of $100 \mu \mathrm{g} / \mathrm{mL}$. Fruit extracts exhibited less activity compared to leaf extracts, while the scavenging effect increased with an increase in the concentration. Also, there was a correlation between antioxidant activity and phenolic compounds. Dastmalchi et al. investigated the chemical composition and antioxidant activity of water-soluble Moldavian balm (Dracocephalum moldavica) in vitro by using DPPH, ABTS, and superoxide activity [95]. The finding confirmed that polar compounds such as caffeic acid and rosmaric acid were responsible for the antioxidant activity observed. 
Mulberry leaves were investigated to determine the antioxidant activity using different solvents [95]. The procedure used DPPH and inhibition of lipid peroxidation methods to evaluate its activity. The results showed that the methanolic extract exhibited the highest yield of total phenolics, and it was the most essential antioxidant in all the methods used. The antioxidant activity of kale (Brassica obraceae L.) has been screened after removing a fat fraction from the samples [96]. The extraction process used methanol to investigate its antioxidant activity while using DPPH scavenging activity as tested method. The works successfully isolated nine phenolic acids using HPLC and MS, and confirmed that the total phenolic content was correlated with DPPH scavenging activity.

In another study, ethanol has been used to estimate the antioxidant activity of sun-dried cashew nuts (Anacardium occidentale L.) skin [97]. First, bioactive compounds were extracted with a protocol including lipid peroxidation, ABTS, and DPPH methods to measure the capability to inhibit oxidation. The results found that epicatechin was the major polyphenol in the extract, which was responsible for antioxidant activity.

Kaviarasan et al. measured the antioxidant and antiradical activity of fenugreek (Trigonella foenum ssp. graecum) seeds in vitro; the results showed that there was a positive relationship between the antiradical activity and phenolic compound content in the extract [98]. Hexane and methanol were used to extract the bioactive compounds and measured the antioxidant activity of Pueraria tuberosa by using ABTS, lipid peroxidation, and superoxide and hydroxyl scavenging activity. An independent study has shown an inhibition of the lipid peroxidation [99].

The rhizome of the lotus (Nelumbo nucifera Gaertn.) has been measured for its antioxidant activity in various solvent extracts using $\beta$ Carotene bleaching and DPPH methods [99]. Methanol extraction had a higher DPPH scavenging activity than acetone. Helichrysum pedunculatum has been tested to determine the antioxidant activity, and total phenolic and flavonoid content [100]. The results demonstrated that whenever the amount of phenolic content and flavonoid content was increased, higher antioxidant activity was obtained. Meot-Duros and Magn screened the leaves of Crithmum maritmum to show if there was any correlation between the antioxidant activity and phenolic content and found a significant correlation between antioxidant activity and phenolic content when methanol was used as the solvent [101].

Another dicot, Tricholepis glaberrima L. (Asteraceae), has been investigated for antioxidant activity using different kinds of extracts [101]. Higher antioxidant activity was found by methanol, and a lower antioxidant activity in both chloroform and aqueous extracts. Sakat et al. investigated Oxalis corniculata L. in order to measure the antioxidant and anti-inflammatory activity employing methanol as a solvent. The IC 50 values of DPPH and nitric acid were about 93 and $73.07 \mu \mathrm{g} / \mathrm{mL}$, respectively [102].

Jain et al. studied Tabernaemontana divaricata $\mathrm{L}$. to determine the phytochemical and free radical scavenging activities in vitro. The results indicated that the antioxidant activity was the same in both ethanol and water extracts, but less in petroleum ether [103].

It has been reported that Ascleipiadaceae and Periplocoideae presented high antioxidant activity, with the presence of a strong correlation between antioxidant activity and phenolic content [103]. Laitonjam and Kongbrailatpam studied the chemical composition and antioxidant activities of Smilax lanceafolia by isolating the flavonol glycoside and steroidal saponin, which showed high antioxidant activity [104]. Spinach (Spinacea olerace L.) is among the most popular vegetables in the world. It was domesticated and first cultivated in West Asia. According to analytical chemistry, spinach is a source of violaxanthin and neoxanthin antioxidants that cannot be commercially produced [105]. Although they may be present, pigments such as carotenoids can be masked by chlorophyll in greenish vegetables such as spinach [106]. B-carotene, lutein, violaxanthin, and neoxanthin are the major carotenoids in raw spinach [107]. Pumpkins belong to the family Cucurbitaceae. This family is classified depending on the texture and shape of stems, such as in Cucurbita pepo, Cucurbita moschata, Cucurbita maxima, and Cucurbita mixta. Nowadays, the market offers a wide variety of vegetables, with pumpkin being one of them because of its many applications for nutrition or decoration [108]. 


\section{Plants Vitamins and Phenolic Compounds as Antioxidants}

\subsection{Phenolic Compounds}

\subsubsection{Phenols and Phenolic Acid}

Phenolic acids contain carboxylic acid in the chemical composition. Hydroxycinnamic and hydroxybenzoic acids are both main pillars of phenolic acids, according to Figure 1A. Moreover, scientists have noted that p-coumaric, caffeic, ferulic, and sinapic acids are main components of the hydroxycinnamic acids (Figure 1A).

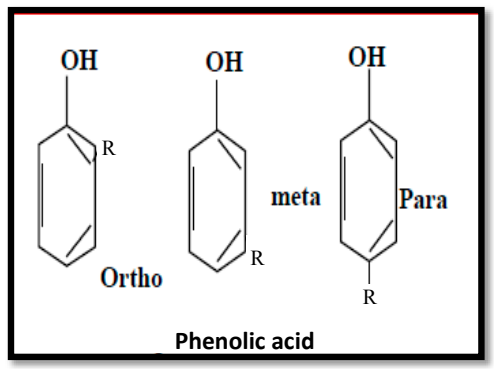

(A)

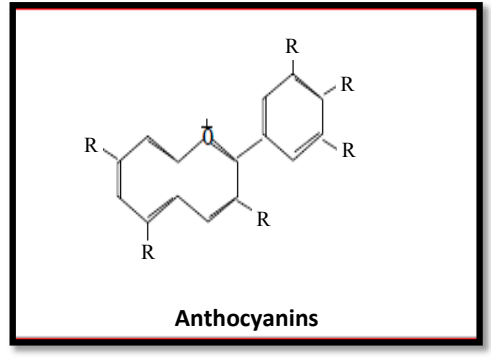

(C)

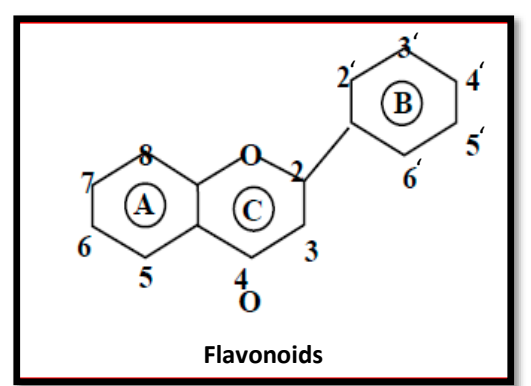

(B)

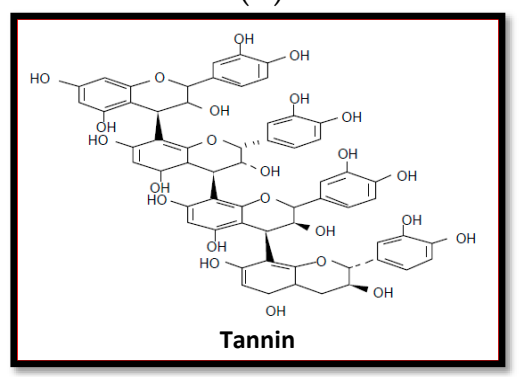

(D)

Figure 1. Chemical structure of phenolic acid (A), flavonoids (B), anthocyanins (C), and tannins (D).

\subsubsection{Flavonoids}

Flavonoids have a low molecular weight (Figure 1B). Flavane is an example of a flavonoid. Flavane contains two benzene rings (Figure 1A,B) within its chemical composition. These two rings connect to each other through a pyrane ring (Figure 1C). Flavones, isoflavones, flavonoids, flavonols, flavanones, anthocyanins, and proanthocyanidins are part of flavonoids according to the flavonoid classification (Figure 1B).

\subsubsection{Anthocyanins}

Anthocyanidins are a simple example of anthocyanins. Anthocyanidins consist of an aromatic ring that is linked to a heterocyclic ring (Figure 1C). Moreover, the heterocyclic ring is connected to the third aromatic ring through a carbon bond [109]. Scientists have noted that anthocyanins are often found in a glycoside form. Moreover, many kinds of anthocyanins are found in nature, making these kinds of phenolic compounds very complex. Scientists have noted that anthocyanins in different kinds of fruit are considered an essential compound that can enrich and increase antioxidant activity (Figure 1C).

\subsubsection{Tannins}

Tannins are natural products present in several plant families, and have large amounts of phenolic rings in the structure. Tannins are classified into two groups: hydrolyzable and condensed. Condensed 
tannins contain flavonoids units with several degrees of condensation. Hydrolyzable tannins are considered a mixture of simple phenols with ester linkages in its structure. There are many factors such as alkaline compounds, mineral acids, and enzymes that have the ability to hydrolyze tannins (Figure 1D) [110].

\subsection{Vitamins Role in Cancer Prevention}

Cancer has been increasing throughout the world. It is the main cause of mortality from year to year. There were 10.4 million new cancer cases registered in 2015, and scientists predict that the number of cancer cases per year will double by 2030 [111]. Recently, many studies have shown rigorous evidence that hydroxyl radicals $(\mathrm{OH} \bullet)$ and the superoxide anion $\left(\mathrm{O}_{2}^{-} \bullet\right)$ are involved in the development of cancer because they are biological reactive oxygen species. Compounds with high reactive oxygen species reduction activity are likely able to prevent cancer's occurrence [112]. As shown previously, fruits and vegetables are the primary source of natural antioxidants, consisting of different kinds of antioxidant compounds such as Vitamin C, Vitamin E, carotenoids, lutein, and lycopene. Some researchers have confirmed that phenolic compounds and polyphenols are secondary plant metabolites, which are considered the best scavengers to prevent the production of free radicals. The United States has an amazing diversity of plant species. Some of them have been used for traditional medicines for a long period of time because of their various desirable activities. Kiwi and pomegranate plants extracts were screened to show the cytotoxic effects on two tumor cell lines ( $L 20 B$ and $R D)$. The results have shown that the means of both L20B and RD cultures were significantly different $(p<0.05)$, and kiwi and pomegranate plant extracts exhibited a strong ability to inhibit the growth rate of L20B and RD cell lines. At concentrations of $1000 \mu \mathrm{g} / \mathrm{mL}$, both extracts showed a high ability to decrease the number of L20B and RD cells when compared with the control [113].

The mixtures of the plant natural products have been screened in order to study their effect on human leukemia cells [114]. The finding confirmed that mixtures of natural products were a good source for human leukemia cell inhibition. Nassr-allah et al. investigated the chemical diversity of natural products from plants in order to test their ability to work as anticancer and antioxidant agents [115]. DPPH assay was used to measure the antioxidant activity for plant extraction while using in vivo and vitro methods in order to measure the anticancer activity. The results confirmed that some natural products from Egyptian flora have the potential for use as therapeutics for diseases such as cancer [116].

The effectiveness of an aqueous extract from willow leaves (Salix safsaf, Salicaceae) against human carcinoma cells has been tested in vivo and in vitro [115]. The findings mentioned that the metabolites for the willow extract could inhibit tumors, thereby enhancing apoptosis and causing DNA damage. The anticancer activity of different extracts from the leaves of the drumstick tree (Moringa oleifera) was screened in order to test against leukemia and hepatocarcinoma cells in vitro. Primary cells harvested from 10 patients with acute lymphoblastic leukemia (ALL) and 15 with acute myeloid leukemia (AML) were significantly killed by hot water and ethanol extracts. Thus, Moringa oleifera may have the potential for use as a natural treatment for diseases such as cancer [117]. Altemimi reported that the phenolic extracts from the olive leaf extract could be used as a source of potential antioxidant and antimicrobial agents [118].

\section{Plants as an Antimicrobial Source}

The antibacterial activity of Punica granatum extracts has been investigated by using various solvents [119]. The water extract had the ability to inhibit Bacillus subtilis and Staphylococcus aureus, but the organic solvents have the ability to inhibit the growth of all the organisms tested. Shariff et al. estimated the antibacterial activity of Rauvolfia tetraphylla and Physalis minima leaves. The chloroform extract was a more powerful inhibitor of pathogenic bacteria [120].

Indian medicinal plants have been shown to have antimicrobial activity [120]. About 77 extracts belonging to these plants have been tested for their antimicrobial ability against eight species of bacteria 
and four species of pathogenic fungi. The findings showed that water extracts of Lantana camara L., Saraca asoca L., Acacia nilotica L., and Justicia zeylanica L. caused the highest growth inhibition of all tested bacteria. The antimicrobial activity was the highest, ranging between 9.375 and $37.5 \mu \mathrm{g} / \mathrm{mL}$ and 75.0 to $300.0 \mu \mathrm{g} / \mathrm{mL}$ against both bacterial and fungal pathogens.

Devi et al. investigated Achyranthes bidentata Blume to determine its phytochemical content and antibacterial activity [121]. The antibacterial ability of the ethanol extract effectively inhibited Bacillus subtilis, Salmonella typhi, and Klebsiella pneumoniae, but was less effective against Pseudomonas species and Staphylococcus aureus [122]. Ethanolic extracts of Gymnema montanum L. have been studied to measure its antimicrobial properties against Salmonella typhi, Pseudomonas aeruginosa, and Candida albicans [121]. The results indicated the highest presence of antimicrobial properties in the leaf extract of G. montanum, correlating to its phenolic compound content. The antimicrobial activity of Piper ribesoides L. from methanolic root extract against Staphylococcus aureus has been reported [123]. Interestingly, a small amount of $3.125 \mathrm{mg} / \mathrm{mL}$ was enough to inhibit harmful bacteria. Leaf extracts of Caesalpinnia pulcherrimma (L.) showed higher antioxidant activity in water and ethanol extracts and lower antioxidant activity in petroleum ether extracts [124]. Torilis japonica L. fruit has been observed to reduce the amount of spores, and the concentration of the vegetative cell was lower than the detection level. Ghosh et al. studied Stevia rebaudiana Bertoni to measure its antimicrobial properties against 10 pathogens [125]. The findings confirmed that Staphylococcus aureus was more susceptible than others [24]. Mahesh and Satish screened some important medicinal plants to show the antibacterial activity on human pathogenic bacteria [126]. Water and methanol were used as solvents to extract the phenolic compounds. The finding confirmed that the methanol extract had a higher antimicrobial activity than the aqueous extract [125].

Moreover, leaf extracts of Acacia nilotica L., Sida cordifolia L., Tinospora cordifolia L., Withania somnifera L., and Ziziphus mauritiana L. have been studied to determine the antibacterial activity against Bacillus subtlis, Escherichia coli, Staphylococus aureus, and Pseudomonas fluorescens, as well as studying the antifungal activity against Aspergillus flavus, Dreschlera turcica, and Fusarium verticilloides [126]. The highest antibacterial activity was noticed in Acacia nilotica and Sida cordifoliain leaves, and the highest antifungal activity was noticed in Acacia nilotica bark. Water and methanol extracts of Samanea saman (Jacq.) exhibited a significant effect against Xanthomonas spp. and human pathogenic bacteria. Pseudarthria viscida root has been studied to measure its antimicrobial activity using ethanol as a solvent. The results showed high antimicrobial activity when compared to standard drugs like ciprofloxacin and griseofulvin.

Ehsan et al. reported a high antimicrobial activity against Staphylococcus aureus using methanol and ethanol extracts for Hopea pariviflora Beddome [127]. Ethanolic extracts of Bryonopsis laciniosa have been investigated for their antimicrobial activity against different Gram-positive and Gram-negative bacteria. The growth of Staphylococcus aureus, Micrococus luteus, and Bacillus cereus was inhibited, as shown by a decrease in the growth zone.

Plumbago zeylanica L. has been screened to measure the antibacterial activity in chloroform extracts to show antimicrobial activity against Escherichia coli, S. typhi, and Staphylococcus aureus [127]. However, Bacillus subtilis and Klebsiella were resistant. Khond et al. studied 55 medicinal plants to measure the antimicrobial activity [128]. The higher antibacterial activities were in the extracts of Madhuca longifolia L., Parkia biglandulosa L., and Pterospermum acerifolium L. compared to the other plants screened. Pavithra et al. screened Evolvulus nummularius L. for its antibacterial activity, finding that Escherichia coli and B. subtilis were the most inhibited by an ethanolic extract [129].

Hygrophila spinosa Andres leaves showed significant antibacterial activity when collected between September to October, with less activity seen during other months [129]. Artemisia pallens L. has been studied for its antimicrobial activity against seven species of bacteria [130]. The results found that Bacillus cereus was more sensitive to A. pallens extracts. Also, a methanolic extract exhibited higher antibacterial activity than the other solvents used. Akroum indicated the antimicrobial activity of some Algerian plants [131]. The results expressed higher antibacterial activity in methanolic extracts of 
Linum capitatum, Camellia sinensis, Allium schoenoprasum, Vicia faba, Citrus paradise, Lippia citriodora, Vaccinium macrocarpon, and Punica granatum. Bajpai et al. screened the antibacterial activity of Pongamia pinnata leaves by using methanol and ethyl acetate extracts to confirm its ability against certain pathogenic bacteria [132]. The results exhibited significant inhibition compared to streptomycin. It has been demonstrated that Memecylon edule has higher antibacterial activity in chloroform extracts compared to other extracts [132]. Gram-negative bacteria were more susceptible to the crude extracts compared to Gram-positive bacteria. Bansal et al. studied plants found in arid zones in order to determine the antibacterial efficiency [133]. An ethanolic extract of Tinospora cordifolia L. inhibited Bacillus cereus and Staphylococcus aureus. Kumar et al. reported Andrographis serpyllifolia L. to have significant antimicrobial activity against tested organisms in methanol extracts of both aerial parts and root [134].

Memecylon malabaricum, Cochlospermum religiosum, and Andrographis serpyllifolia have been rested for their possible antimicrobial activity [135,136]. Moderate activity against both Gram-positive and Gram-negative bacteria was observed. The antimicrobial activity of an ethanolic extract of Anethum graveolens was better than the aqueous extract. Khanahmadi et al. [137] found a higher antibacterial activity against Gram-positive bacteria compared to Gram-negative bacteria when an ethanolic extract of Smyrnium cordifolium Boiss was used [136,137]. Koperuncholan et al. studied some medicinal plants of the south eastern slopes of the Western Ghats [138]. Gram-positive bacteria were more sensitive than Gram-negative bacteria to the plant extracts. Niranjan et al. screened Schrebera swietenioides Roxb to measure the effectiveness against human pathogenic bacteria [139]. Water and methanol extracts were most effective to prohibit growth of all the harmful bacteria tested.

Different studies have isolated tannins and saponins from some Indian medicinal plants, testing the antibacterial activity against Klebsiella pneumoniae [139,140]. Ethanol extracts of Tinospora cordifolia strongly inhibited Bacillus cereus and Staphylococcus aureus. Also, significant antibacterial activity from ethanolic extracts of Coleus aromaticus L. has been found. The most effective range of inhibition was at concentrations of 25-39 $\mathrm{g} / \mathrm{mL}$. Vinothkumar et al. evaluated a Andrographis paniculata L. leaf extract's ability to inhibit the growth of Gram-positive and Gram-negative bacteria. The results found that aqueous extracts inhibited harmful microbes [134].

A positive effect of pumpkin has been observed by investigating its antimicrobial activity against Staphylococcus aureus, Bacillus subtillus, Escherichia coli, and Pseudomonas. aeruginosa. Three different solvents were used to prepare the extracts: water, chloroform, and alcohol. The results showed that the alcohol extract was more powerful than both water and chloroform extracts. Staphylococcus aureus was sensitive to all extracts. Recently, the novel antimicrobial activity of ultrasonicated spinach leaf extracts using random amplification of polymorphic DNA (RAPD) markers and electron microscopy against both Gram-positive and Gram-negative bacteria has been revealed [134]. RAPD is an emerging technique used for diagnostic mutation detection within a genome. The range of the minimum inhibitory concentrations (MICs) of the extracted leaf spinach antimicrobial substances against Escherichia coli and Staphylococcus aureus was observed between 60 and $100 \mathrm{mg} / \mathrm{mL}$. The optimal extraction conditions were at $45{ }^{\circ} \mathrm{C}$, ultrasound power of $44 \%$, and an extraction time of 23 minutes. The study showed that the treated bacterial cells appeared to be damaged by a reduction in cell number. In fact, it was inferred that spinach leaf extracts exert bactericidal activity by inducing mutations in DNA and causing cell wall disruptions.

\section{Conclusions}

In summary, plant extracts showed strong antioxidant capacity both in vitro and in vivo, and the extracts can be considered a good source of natural antioxidants and antimicrobials. Polyphenol extraction from plants using fast and appropriate techniques is a low-cost method due to the reduction in the amount of solvent used, in addition to avoiding the need for longer extraction times compared to the conventional extraction method. Moreover, natural bioactive compounds have been found to interfere with and prevent all kinds of cancer. Flavonoids have been shown to work as 
anti-tumor (benign, melanoma) agents involving a free radicals quenching mechanism (i.e., $\mathrm{OH}, \mathrm{ROO}$ ). In fact, many studies have shown that flavonoids play significant multiple roles including mutagenic, cell damage, and carcinogenic, due to their acceleration of different aging factors. In addition to antioxidant activity, the inhibition of cancer development by phenolic compounds relies on a number of basic cellular mechanisms. More comprehensive studies related to these compounds will enhance pharmaceutical exploration in the field of carcinogenic disease prevention.

Supplementary Materials: The following are available online at www.mdpi.com/2223-7747/6/4/42/s1.

Acknowledgments: The authors would like to thank the Higher Committee for Education Development in Iraq (HCED) for the financial support to achieve this work and Stuart Alan Walters of the Department of Plant, Soil and Agricultural Systems, College of Agricultural Sciences, Southern Illinois University.

Author Contributions: Ammar Altemimi drafted the manuscript; Naoufal Lakhssassi and Azam Baharlouei edited the manuscript and made the corresponding figures and tables; Dennis G. Watson and David A. Lightfoot edited and commented on the manuscript. All authors have read and approved the final manuscript.

Conflicts of Interest: The authors declare no conflicts of interest.

\section{References}

1. Jakubowski, W.; Bartosz, G. Estimation of oxidative stress in saccharomyces cerevisae with fluorescent probes. Int. J. Biochem. Cell Biol. 1997, 29, 1297-1301. [CrossRef]

2. Naczk, M.; Shahidi, F. Phenolics in cereals, fruits and vegetables: Occurrence, extraction and analysis. J. Pharm. Biomed. Anal. 2006, 41, 1523-1542. [CrossRef] [PubMed]

3. Suffredini, I.B.; Sader, H.S.; Gonçalves, A.G.; Reis, A.O.; Gales, A.C.; Varella, A.D.; Younes, R.N. Screening of antibacterial extracts from plants native to the brazilian amazon rain forest and atlantic forest. Braz. J. Med. Biol. Res. 2004, 37, 379-384. [CrossRef] [PubMed]

4. Boots, A.W.; Haenen, G.R.; Bast, A. Health effects of quercetin: From antioxidant to nutraceutical. Eur. J. Pharmacol. 2008, 585, 325-337. [CrossRef] [PubMed]

5. Valko, M.; Rhodes, C.J.; Moncol, J.; Izakovic, M.; Mazur, M. Free radicals, metals and antioxidants in oxidative stress-induced cancer. Chem. Biol. Interact. 2006, 160, 1-40. [CrossRef] [PubMed]

6. Ames, B.N.; Shigenaga, M.K.; Hagen, T.M. Oxidants, antioxidants, and the degenerative diseases of aging. Proc. Natl. Acad. Sci. USA 1993, 90, 7915-7922. [CrossRef] [PubMed]

7. Duthie, S.J.; Ma, A.; Ross, M.A.; Collins, A.R. Antioxidant supplementation decreases oxidative DNA damage in human lymphocytes. Cancer Res. 1996, 56, 1291-1295. [PubMed]

8. Vivekananthan, D.P.; Penn, M.S.; Sapp, S.K.; Hsu, A.; Topol, E.J. Use of antioxidant vitamins for the prevention of cardiovascular disease: Meta-analysis of randomised trials. Lancet 2003, 361, 2017-2023. [CrossRef]

9. Wong, P.Y.Y.; Kitts, D.D. Studies on the dual antioxidant and antibacterial properties of parsley (petroselinum crispum) and cilantro (coriandrum sativum) extracts. Food Chem. 2006, 97, 505-515. [CrossRef]

10. Ruan, Z.P.; Zhang, L.L.; Lin, Y.M. Evaluation of the antioxidant activity of syzygium cumini leaves. Molecules 2008, 13, 2545-2556. [CrossRef] [PubMed]

11. Koffi, E.; Sea, T.; Dodehe, Y.; Soro, S. Effect of solvent type on extraction of polyphenols from twenty three ivorian plants. J. Anim. Plant Sci. 2010, 5, 550-558.

12. Anokwuru, C.P.; Anyasor, G.N.; Ajibaye, O.; Fakoya, O.; Okebugwu, P. Effect of extraction solvents on phenolic, flavonoid and antioxidant activities of three nigerian medicinal plants. Nat. Sci. 2011, 9, 53-61.

13. Ballard, T.S.; Mallikarjunan, P.; Zhou, K.; O'Keefe, S. Microwave-assisted extraction of phenolic antioxidant compounds from peanut skins. Food Chem. 2010, 120, 1185-1192. [CrossRef]

14. Kingston, H.M.; Jessie, L.B. Introduction to Microwave Sample Preparation; American Chemical Society: Washington, DC, USA, 1998.

15. Suzara, S.; Costa, D.A.; Gariepyb, Y.; Rochaa, S.C.S.; Raghavanb, V. Spilanthol extraction using microwave: Calibration curve for gas chromatography. Chem. Eng. Trans. 2013, 32, 1783-1788.

16. Li, H.; Deng, Z.; Wu, T.; Liu, R.; Loewen, S.; Tsao, R. Microwave-assisted extraction of phenolics with maximal antioxidant activities in tomatoes. Food Chem. 2012, 130, 928-936. [CrossRef] 
17. Tsubaki, S.; Sakamoto, M.; Azuma, J. Microwave-assisted extraction of phenolic compounds from tea residues under autohydrolytic conditions. Food Chem. 2000, 123, 1255-1258. [CrossRef]

18. Christophoridou, S.; Dais, P.; Tseng, L.H.; Spraul, M. Separation and identification of phenolic compounds in olive oil by coupling high-performance liquid chromatography with postcolumn solid-phase extraction to nuclear magnetic resonance spectroscopy (lc-spe-nmr). J. Agric. Food Chem. 2005, 53, 4667-4679. [CrossRef] [PubMed]

19. Williams, O.J.; Raghavan, G.S.V.; Orsat, V.; Dai, J. Microwave-assisted extraction of capsaicinoids from capsicum fruit. J. Food Biochem. 2004, 28, 113-122. [CrossRef]

20. Garcia-Salas, P.; Morales-Soto, A.; Segura-Carretero, A.; Fernandez-Gutierrez, A. Phenolic-compound-extraction systems for fruit and vegetable samples. Molecules 2010, 15, 8813-8826. [CrossRef] [PubMed]

21. Corrales, M.; Toepfl, S.; Butz, P.; Knorr, D.; Tauscher, B. Extraction of anthocyanins from grape by-products assisted by ultrasonics, high hydrostatic pressure or pulsed electric fields: A comparison. Innov. Food Sci. Emerg. Technol. 2008, 9, 85-91. [CrossRef]

22. Tabaraki, R.; Nateghi, A. Optimization of ultrasonic-assisted extraction of natural antioxidants from rice bran using response surface methodology. Ultrason. Sonochem. 2011, 18, 1279-1286. [CrossRef] [PubMed]

23. Albu, S.; Joyce, E.; Paniwnyk, L.; Lorimer, J.P.; Mason, T.J. Potential for the use of ultrasound in the extraction of antioxidants from rosmarinus officinalis for the food and pharmaceutical industry. Ultrason. Sonochem. 2004, 11, 261-265. [CrossRef] [PubMed]

24. Cho, W.I.; Choi, J.B.; Lee, K.; Chung, M.S.; Pyun, Y.R. Antimicrobial activity of torilin isolated from torilis japonica fruit against bacillus subtilis. J. Food Sci. 2008, 73, 37-46. [CrossRef] [PubMed]

25. Barbero, G.F.; Liazid, A.; Palma, M.; Barroso, C.G. Ultrasound-assisted extraction of capsaicinoids from peppers. Talanta 2008, 75, 1332-1337. [CrossRef] [PubMed]

26. Luque-García, J.L.; Luque de Castro, M.D. Ultrasound: A powerful tool for leaching. TrAC Trends Anal. Chem. 2003, 22, 41-47. [CrossRef]

27. Mulinacci, N.; Prucher, D.; Peruzzi, M.; Romani, A.; Pinelli, P.; Giaccherini, C.; Vincieri, F.F. Commercial and laboratory extracts from artichoke leaves: Estimation of caffeoyl esters and flavonoidic compounds content. J. Pharm. Biomed. Anal. 2004, 34, 349-357. [CrossRef]

28. Altemimi, A.W.; Watson, D.G.; Kinsel, M.; Lightfoot, D.A. Simultaneous extraction, optimization, and analysis of flavonoids and polyphenols from peach and pumpkin extracts using a tlc-densitometric method. Chem. Cent. J. 2015, 9, 1-15. [CrossRef] [PubMed]

29. Altemimi, A.; Lightfoot, D.A.; Kinsel, M.; Watson, D.G. Employing response surface methodology for the optimization of ultrasound assisted extraction of lutein and $\beta$-carotene from spinach. Molecules 2015, 20, 6611-6625. [CrossRef] [PubMed]

30. Sarajlija, H.; Čkelj, N.; Novotni, D.; Mršić, G.; Ćurić, M.; Brncic, M.; Curic, D. Preparation of flaxseed for lignan determination by gas chromatography-mass spectrometry method. Czech J. Food Sci. 2012, 30, 45-52.

31. Popova, I.E.; Hall, C.; Kubátová, A. Determination of lignans in flaxseed using liquid chromatography with time-of-flight mass spectrometry. J. Chromatogr. A 2009, 1216, 217-229. [CrossRef] [PubMed]

32. Zhang, Z.; Pang, X.; Xuewu, D.; Ji, Z.; Jiang, Y. Role of peroxidase in anthocyanin degradation in litchi fruit pericarp. Food Chem. 2005, 90, 47-52. [CrossRef]

33. Kemp, W. Energy and electromagnetic spectrum. In Organic Spectroscopy; Kemp, W., Ed.; Macmillan Press: London, UK, 1991; pp. 1-7.

34. Kemp, W. Infrared spectroscopy. In Organic Spectroscopy; Macmillan Press Ltd.: London, UK, 1991; pp. $19-56$.

35. Urbano, M.; Luque de Castro, M.D.; Pérez, P.M.; García-Olmo, J.; Gómez-Nieto, M.A. Ultraviolet-visible spectroscopy and pattern recognition methods for differentiation and classification of wines. Food Chem. 2006, 97, 166-175. [CrossRef]

36. Cherkaoui, A.; Hibbs, J.; Emonet, S.; Tangomo, M.; Girard, M.; Francois, P.; Schrenzel, J. Comparison of two matrix-assisted laser desorption ionization-time of flight mass spectrometry methods with conventional phenotypic identification for routine identification of bacteria to the species level. J. Clin. Microbiol. 2010, 48, 1169-1175. [CrossRef] [PubMed]

37. Beckey, H.D. 1-Theory of Field Ionization (FI) and Field Emission (FE); Pergamon: Bergama, Turkey, 1971.

38. Beckey, H.D. 2-Field Ionization Sources; Pergamon: Bergama, Turkey, 1971.

39. Beckey, H.D. 3-Application of the FI Mass Spectrometer to Physico-Chemical Problems; Pergamon: Bergama, Turkey, 1971. 
40. Beckey, H.D. 4-Qualitative Analyses with the Fi Mass Spectrometer; Pergamon: Bergama, Turkey, 1971.

41. Kemp, W. Nuclear magnetic resonance spectroscopy. In Organic Spectroscopy; Kemp, W., Ed.; Macmillan Press: London, UK, 1991; pp. 101-240.

42. Halliwell, B.; Murcia, M.A.; Chirico, S.; Aruoma, O.I. Free radicals and antioxidants in food and in vivo: What they do and how they work. Crit. Rev. Food Sci. Nutr. 1995, 35, 7-20. [CrossRef] [PubMed]

43. Clemente, T.E.; Cahoon, E.B. Soybean oil: Genetic approaches for modification of functionality and total content. Plant Physiol. 2009, 151, 1030-1040. [CrossRef] [PubMed]

44. Lakhssassi, N.; Zhou, Z.; Liu, S.; Colantonio, V.; AbuGhazaleh, A.; Meksem, K. Characterization of the fad2 gene family in soybean reveals the limitations of gel-based tilling in genes with high copy number. Front. Plant Sci. 2017, 8, 324. [CrossRef] [PubMed]

45. Mensink, R.P.; Katan, M.B. Effect of dietary trans fatty acids on high-density and low-density lipoprotein cholesterol levels in healthy subjects. N. Engl. J. Med. 1990, 323, 439-445. [CrossRef] [PubMed]

46. Kris-Etherton, P.M.; Yu, S.; Etherton, T.D.; Morgan, R.; Moriarty, K.; Shaffer, D. Fatty acids and progression of coronary artery disease. Am. J. Clin. Nutr. 1997, 65, 1088-1090. [PubMed]

47. Kris-Etherton, P.M.; Yu, S. Individual fatty acid effects on plasma lipids and lipoproteins: Human studies. Am. J. Clin. Nutr. 1997, 65, 1628-1644.

48. Byfield, G.E.; Xue, H.; Upchurch, R.G. Two genes from soybean encoding soluble $\delta 9$ stearoyl-acp desaturases. Crop Sci. 2006, 46, 840-846. [CrossRef]

49. Lakhssassi, N.; Colantonio, V.; Flowers, N.D.; Zhou, Z.; Henry, J.S.; Liu, S.; Meksem, K. Stearoyl-acyl carrier protein desaturase mutations uncover an impact of stearic acid in leaf and nodule structure. Plant Physiol. 2017, 174, 1531-1543. [CrossRef] [PubMed]

50. St Angelo, A.J. Lipid oxidation on foods. Crit. Rev. Food Sci. Nutr. 1996, 36, 175-224. [CrossRef] [PubMed]

51. Javanmardi, J.; Stushnoff, C.; Locke, E.; Vivanco, J.M. Antioxidant activity and total phenolic content of iranian ocimum accessions. Food Chem. 2003, 83, 547-550. [CrossRef]

52. Negi, P.S.; Chauhan, A.S.; Sadia, G.A.; Rohinishree, Y.S.; Ramteke, R.S. Antioxidant and antibacterial activities of various seabuckthorn (hippophae rhamnoides 1.) seed extracts. Food Chem. 2005, 92, 119-124. [CrossRef]

53. Baharlouei, A.; Sharifi-Sirchi, G.R.; Bonjar, G.H.S. Identification of an antifungal chitinase from a potential biocontrol agent, streptomyces plicatus strain 101, and its new antagonistic spectrum of activity. Philipp. Agric. Sci. 2010, 93, 439-445.

54. Baharlouei, A.; Sharifi-Sirchi, G.R.; Bonjar, G.H.S. Biological control of sclerotinia sclerotiorum (oilseed rape isolate) by an effective antagonist streptomyces. Afr. J. Biotechnol. 2011, 10, 5785-5794.

55. Ruberto, G.; Baratta, M.T.; Deans, S.G.; Dorman, H.J.D. Antioxidant and antimicrobial activity of foeniculum vulgare and crithmum maritimum essential oils. Planta Medica 2000, 66, 687-693. [CrossRef] [PubMed]

56. Butterfield, N.J. Implications for the evolution of sex, multicellularity, and the mesoproterozoic/neoproterozoic radiation of eukaryotes. Paleobiology 2000, 26, 386-404. [CrossRef]

57. Ashawat, M.S.; Shailendra, S.; Swarnlata, S. In vitro antioxidant activity of ethanolic extracts of centella asiatica, punica granatum, glycyrrhiza glabra and areca catechu. Res. J. Med. Plants 2007, 1, 13-16.

58. Londonkar, R.; Kamble, A. Evaluation of free radical scavenging activity of pandanus odoratissimus. Int. J. Pharmacol. 2009, 5, 377-380. [CrossRef]

59. Zahin, M.; Aqil, F.; Ahmad, I. The in vitro antioxidant activity and total phenolic content of four indian medicinal plants. J. Appl. Biol. Sci. 2007, 1, 87-90.

60. Block, G.; Patterson, B.; Subar, A. Fruit, vegetables, and cancer prevention: A review of the epidemiological evidence. Nutr. Cancer 1992, 18, 1-29. [CrossRef] [PubMed]

61. Pratt, D.E.; Watts, B.M. The antioxidant activity of vegetable extracts i. Flavone aglyconesa. J. Food Sci. 1964, 29, 27-33. [CrossRef]

62. Plumb, G.W.; García-Conesa, M.T.; Kroon, P.A.; Rhodes, M.; Ridley, S.; Williamson, G. Metabolism of chlorogenic acid by human plasma, liver, intestine and gut microflora. J. Sci. Food Agric. 1999, 79, 390-392. [CrossRef]

63. Frankel, E.N.M.; Meyer, A. Antioxidants in grapes and grape juices and their potential health effects. Pharm. Biol. 1998, 36, 1-7. [CrossRef]

64. Wangensteen, H.; Miron, A.; Alamgir, M.; Rajia, S.; Samuelsen, A.B.; Malterud, K.E. Antioxidant and 15-lipoxygenase inhibitory activity of rotenoids, isoflavones and phenolic glycosides from sarcolobus globosus. Fitoterapia 2006, 77, 290-295. [CrossRef] [PubMed] 
65. Monagas, M.; Gómez-Cordovés, C.; Bartolomeä, B.; Laureano, O.; Ricardo da Silva, J.M. Monomeric, oligomeric, and polymeric flavan-3-ol composition of wines and grapes from vitis vinifera l. Cv. Graciano, tempranillo, and cabernet sauvignon. J. Agric. Food Chem. 2003, 51, 6475-6481. [CrossRef] [PubMed]

66. Khan, S.A.; Beekwilder, J.; Schaart, J.G.; Mumm, R.; Soriano, J.M.; Jacobsen, E.; Schouten, H.J. Differences in acidity of apples are probably mainly caused by a malic acid transporter gene on $\lg 16$. Tree Genet. Genomes 2013, 9, 475-487. [CrossRef]

67. Jugde, H.; Nguy, D.; Moller, I.; Cooney, J.M.; Atkinson, R.G. Isolation and characterization of a novel glycosyltransferase that converts phloretin to phlorizin, a potent antioxidant in apple. FEBS J. 2008, 275, 3804-3814. [CrossRef] [PubMed]

68. Huang, Y.F.; Doligez, A.; Fournier-Level, A.; Le Cunff, L.; Bertrand, Y.; Canaguier, A.; Morel, C.; Miralles, V.; Veran, F.; Souquet, J.M.; et al. Dissecting genetic architecture of grape proanthocyanidin composition through quantitative trait locus mapping. BMC Plant Biol. 2012, 12, 30. [CrossRef] [PubMed]

69. Takos, A.M.; Ubi, B.E.; Robinson, S.P.; Walker, A.R. Condensed tannin biosynthesis genes are regulated separately from other flavonoid biosynthesis genes in apple fruit skin. Plant Sci. 2006, 170, 487-499. [CrossRef]

70. Soong, Y.Y.; Barlow, P.J. Antioxidant activity and phenolic content of selected fruit seeds. Food Chem. 2004, 88, 411-417. [CrossRef]

71. Abdille, M.H.; Singh, R.P.; Jayaprakasha, G.K.; Jena, B.S. Antioxidant activity of the extracts from dillenia indica fruits. Food Chem. 2005, 90, 891-896. [CrossRef]

72. Juntachote, T.; Berghofer, E. Antioxidative properties and stability of ethanolic extracts of holy basil and galangal. Food Chem. 2005, 92, 193-202. [CrossRef]

73. Liyana-Pathirana, C.M.; Shahidi, F.; Alasalvar, C. Antioxidant activity of cherry laurel fruit (laurocerasus officinalis roem.) and its concentrated juice. Food Chem. 2006, 99, 121-128. [CrossRef]

74. Orhan, I.; Kartal, M.; Naz, Q.; Ejaz, A.; Yilmaz, G.; Kan, Y.; Konuklugil, B.; Şener, B.; Iqbal Choudhary, M. Antioxidant and anticholinesterase evaluation of selected turkish salvia species. Food Chem. 2007, 103, 1247-1254. [CrossRef]

75. Rathee, J.S.; Hassarajani, S.A.; Chattopadhyay, S. Antioxidant activity of mammea longifolia bud extracts. Food Chem. 2006, 99, 436-443. [CrossRef]

76. Baskar, R.; Rajeswari, V.; Kumar, T.S. In vitro antioxidant studies in leaves of annona species. Indian J. Exp. Biol. 2007, 45, 480-485. [PubMed]

77. Lu, Y.; Yeap, F.L. Antioxidant activities of polyphenols from sage (salvia officinalis). Food Chem. 2001, 75, 197-202. [CrossRef]

78. Zhao, G.R.; Xiang, Z.J.; Ye, T.X.; Yuan, Y.J.; Guo, Z.X. Antioxidant activities of salvia miltiorrhiza and panax notoginseng. Food Chem. 2006, 99, 767-774. [CrossRef]

79. Singh, R.P.; Chidambara Murthy, K.N.; Jayaprakasha, G.K. Studies on the antioxidant activity of pomegranate (punica granatum) peel and seed extracts using in vitro models. J. Agric. Food Chem. 2002, 50, 81-86. [CrossRef] [PubMed]

80. Ćetković, G.S.; Djilas, S.M.; Čanadanović-Brunet, J.M.; Tumbas, V.T. Antioxidant properties of marigold extracts. Food Res. Int. 2004, 37, 643-650. [CrossRef]

81. Siddhuraju, P.; Manian, S. The antioxidant activity and free radical-scavenging capacity of dietary phenolic extracts from horse gram (macrotyloma uniflorum (lam.) verdc.) seeds. Food Chem. 2007, 105, 950-958. [CrossRef]

82. Samak, G.; Shenoy, R.P.; Manjunatha, S.M.; Vinayak, K.S. Superoxide and hydroxyl radical scavenging actions of botanical extracts of wagatea spicata. Food Chem. 2009, 115, 631-634. [CrossRef]

83. Barla, A.; Öztürk, M.; Kültür, Ş.; Öksüz, S. Screening of antioxidant activity of three euphorbia species from turkey. Fitoterapia 2007, 78, 423-425. [CrossRef] [PubMed]

84. Pinelo, M.; Rubilar, M.; Sineiro, J.; Núñez, M.J. Extraction of antioxidant phenolics from almond hulls (prunus amygdalus) and pine sawdust (pinus pinaster). Food Chem. 2004, 85, 267-273. [CrossRef]

85. Ibrahim, N.A.; El-Seedi, H.R.; Mohammed, M.M. Phytochemical investigation and hepatoprotective activity of cupressus sempervirens 1. Leaves growing in egypt. Nat. Prod. Res. 2007, 21, 857-866. [CrossRef] [PubMed]

86. Kaur, R.; Thind, T.S.; Singh, B.; Arora, S. Inhibition of lipid peroxidation by extracts/subfractions of chickrassy (chukrasia tabularis a. Juss.). Die Naturwissenschaften 2009, 96, 129-133. [CrossRef] [PubMed] 
87. Singh, G.; Marimuthu, P.; de Heluani, C.S.; Catalan, C. Chemical constituents and antimicrobial and antioxidant potentials of essential oil and acetone extract of nigella sativa seeds. J. Sci. Food Agric. 2005, 85, 2297-2306. [CrossRef]

88. Tiwari, O.P.; Tripathi, Y.B. Antioxidant properties of different fractions of vitex negundo linn. Food Chem. 2007, 100, 1170-1176. [CrossRef]

89. Zin, Z.M.; Abdul-Hamid, A.; Osman, A. Antioxidative activity of extracts from mengkudu (Morinda citrifolia L.) root, fruit and leaf. Food Chem. 2002, 78, 227-231. [CrossRef]

90. Oktay, M.; Gülçin, İ.; Küfrevioğlu, Ö.İ. Determination of in vitro antioxidant activity of fennel (foeniculum vulgare) seed extracts. LWT Food Sci. Technol. 2003, 36, 263-271. [CrossRef]

91. Parejo, I.; Viladomat, F.; Bastida, J.; Rosas-Romero, A.; Saavedra, G.; Murcia, M.A.; Jimenez, A.M.; Codina, C. Investigation of bolivian plant extracts for their radical scavenging activity and antioxidant activity. Life Sci. 2003, 73, 1667-1681. [CrossRef]

92. Harish, R.; Shivanandappa, T. Antioxidant activity and hepatoprotective potential of phyllanthus niruri. Food Chem. 2006, 95, 180-185. [CrossRef]

93. Ajila, C.M.; Naidu, K.A.; Bhat, S.G.; Rao, U.J.S.P. Bioactive compounds and antioxidant potential of mango peel extract. Food Chem. 2007, 105, 982-988. [CrossRef]

94. Chen, H.Y.; Yen, G.C. Antioxidant activity and free radical-scavenging capacity of extracts from guava (psidium guajava 1.) leaves. Food Chem. 2007, 101, 686-694. [CrossRef]

95. Dastmalchi, K.; Damien Dorman, H.J.; Koşar, M.; Hiltunen, R. Chemical composition and in vitro antioxidant evaluation of a water-soluble moldavian balm (dracocephalum moldavica 1.) extract. LWT Food Sci. Technol. 2007, 40, 239-248. [CrossRef]

96. Arabshahi-Delouee, S.; Urooj, A. Antioxidant properties of various solvent extracts of mulberry (morus indica 1.) leaves. Food Chem. 2007, 102, 1233-1240. [CrossRef]

97. Ayaz, F.A.; Ayaz, S.; Alpay-Karaoglu, S.; Gruz, J.; Valentová, K.; Ulrichová, J.; Strnad, M. Phenolic acid contents of kale (Brassica oleraceae L. Var. Acephala dc.) extracts and their antioxidant and antibacterial activities. Food Chem. 1976, 7, 3. [CrossRef]

98. Kaviarasan, S.; Naik, G.H.; Gangabhagirathi, R.; Anuradha, C.V.; Priyadarsini, K.I. In vitro studies on antiradical and antioxidant activities of fenugreek (trigonella foenum graecum) seeds. Food Chem. 2007, 103, 31-37. [CrossRef]

99. Pandey, N.; Tripathi, Y.B. Antioxidant activity of tuberosin isolated from pueraria tuberose linn. J. Inflamm. 2010, 7, 47. [CrossRef] [PubMed]

100. Yang, D.; Wang, Q.; Ke, L.; Jiang, J.; Ying, T. Antioxidant activities of various extracts of lotus (nelumbo nuficera gaertn) rhizome. Asia Pac. J. Clin. Nutr. 2007, 16, 158-163. [PubMed]

101. Meot-Duros, L.; Magne, C. Antioxidant activity and phenol content of crithmum maritimum 1 . Leaves. Plant Physiol. Biochem. 2009, 47, 37-41. [CrossRef] [PubMed]

102. Sakat, S.; Juvekar, R.A.; Gambhire, M.N.; Juvekar, M.; Wankhede, S. In vitro antioxidant and anti-inflammatory activity of methanol extract of oxalis corniculata linn. Int. J. Pharm. Pharm. Sci. 2010, 2, 146-155.

103. Jain, S.; Jain, A.; Jain, N.; Jain, D.K.; Balekar, N. Phytochemical investigation and evaluation of in vitro free radical scavenging activity of tabernaemontana divaricata linn. Nat. Prod. Res. 2010, 24, 300-304. [CrossRef] [PubMed]

104. Laitonjam, W.S.; Kongbrailatpam, B.D. Studies on the chemical constituents and antioxidant activities of extracts from the roots of smilax lanceaefolia roxb. Nat. Prod. Res. 2010, 24, 1168-1176. [CrossRef] [PubMed]

105. Inbaraj, B.S.; Chien, J.T.; Chen, B.H. Improved high performance liquid chromatographic method for determination of carotenoids in the microalga chlorella pyrenoidosa. J. Chromatogr. A 2006, 1102, 193-199. [CrossRef] [PubMed]

106. Gandul-Rojas, B.; Cepero, M.R.; Minguez-Mosquera, M.I. Chlorophyll and carotenoid patterns in olive fruits, olea europaea cv. Arbequina. J. Agric. Food Chem. 1999, 47, 2207-2212. [CrossRef] [PubMed]

107. Ren, D.; Zhang, S. Separation and identification of the yellow carotenoids in Potamogeton crispus L. Food Chem. 2008, 106, 410-414. [CrossRef]

108. Alves-Rodrigues, A.; Shao, A. The science behind lutein. Toxicol. Lett. 2004, 150, 57-83. [CrossRef] [PubMed]

109. Altemimi, A.; Lakhssassi, N.; Abu-Ghazaleh, A.; Lightfoot, D.A. Evaluation of the antimicrobial activities of ultrasonicated spinach leaf extracts using rapd markers and electron microscopy. Arch. Microbiol. 2017, 1-13. [CrossRef] [PubMed] 
110. Konczak, I.; Zhang, W. Anthocyanins-More than nature's colours. J. Biomed. Biotechnol. 2004, 2004, $239-240$. [CrossRef] [PubMed]

111. Vermerris, W.; Nicholson, R. Phenolic Compound Biochemistry Book; Springer: Dordrecht, The Netherland, 2006.

112. Hursting, S.D.; Slaga, T.J.; Fischer, S.M.; DiGiovanni, J.; Phang, J.M. Mechanism-based cancer prevention approaches: Targets, examples, and the use of transgenic mice. J. Natl. Cancer Inst. 1999, 91, 215-225. [CrossRef] [PubMed]

113. Cai, Y.; Luo, Q.; Sun, M.; Corke, H. Antioxidant activity and phenolic compounds of 112 traditional chinese medicinal plants associated with anticancer. Life Sci. 2004, 74, 2157-2184. [CrossRef] [PubMed]

114. Palanisamy, U.; Cheng, H.M.; Masilamani, T.; Subramaniam, T.; Ling, L.T.; Radhakrishnan, A.K. Rind of the rambutan, nephelium lappaceum, a potential source of natural antioxidants. Food Chem. 2008, 109, 54-63. [CrossRef] [PubMed]

115. Nassr-allah, A.A.; Aboul-enein, K.M.; Lightfoot, D.A.; Cocchetto, A.; El-shemy, H.A. Anti-cancer and anti-oxidant activity of some egyptian medicinal plants. J. Med. Plants Res. 2009, 3, 799-808.

116. El-Shemy, H.A.; Aboul-Enein, K.M.; Lightfoot, D.A. Predicting in silico which mixtures of the natural products of plants might most effectively kill human leukemia cells? Evid.-Based Complement. Altern. Med. 2013, 2013, 801501. [CrossRef] [PubMed]

117. El-Shemy, H.A.; Aboul-Enein, A.M.; Aboul-Enein, K.M.; Fujita, K. Willow leaves' extracts contain anti-tumor agents effective against three cell types. PLoS ONE 2007, 2, e178. [CrossRef] [PubMed]

118. Altemimi, A.B. A study of the protective properties of iraqi olive leaves against oxidation and pathogenic bacteria in food applications. Antioxidants 2017, 6, 34. [CrossRef] [PubMed]

119. Gil, M.I.; Tomas-Barberan, F.A.; Hess-Pierce, B.; Kader, A.A. Antioxidant capacities, phenolic compounds, carotenoids, and vitamin c contents of nectarine, peach, and plum cultivars from california. J. Agric. Food Chem. 2002, 50, 4976-4982. [CrossRef] [PubMed]

120. Shariff, N.; Sudarshana, M.S.; Umesha, S.; Hariprasad, P. Antimicrobial activity of rauvolfia tetraphylla and physalis minima leaf and callus extracts. Afr. J. Biotechnol. 2006, 5, 946-950.

121. Devi, P.U.; Murugan, S.; Suja, S.; Selvi, S.; Chinnaswamy, P.; Vijayanand, E. Antibacterial, in vitro lipid per oxidation and phytochemical observation on achyranthes bidentata blume. Pak. J. Nutr. 2007, 6, 447-451. [CrossRef]

122. Dabur, R.; Gupta, A.; Mandal, T.K.; Singh, D.D.; Bajpai, V.; Gurav, A.M.; Lavekar, G.S. Antimicrobial activity of some indian medicinal plants. Afr. J. Tradit. Complement. Altern. Med. 2007, 4, 313-318. [CrossRef] [PubMed]

123. Ramkumar, K.M.; Rajaguru, P.; Latha, M.; Ananthan, R. Ethanol extract of gymnema montanum leaves reduces glycoprotein components in experimental diabetes. Nutr. Res. 2007, 27, 97-103. [CrossRef]

124. Zakaria, Z.; Sreenivasan, S.; Mohamad, M. Antimicrobial activity of piper ribesoides root extract against staphylococcus aureus. J. Appl. Biol. Sci. 2007, 1, 87-90.

125. Ghosh, S.; Subudhi, E.; Nayak, S. Antimicrobial assay of stevia rebaudiana bertoni leaf extracts against 10 pathogens. Int. J. Integr. Biol. 2008, 2, 1-5.

126. Mahesh, B.; Satish, S. Antimicrobial activity of some important medicinal plant against plant and human pathogens. World J. Agric. Sci. 2008, 4, 839-843.

127. Ehsan, B.R. Antimicrobial activity of the ethanolic extract of bryonopsis laciniosa leaf, stem, fruit and seed. Afr. J. Biotechnol. 2009, 8, 565-3567.

128. Khond, M.; Bhosale, J.D.; Tasleem, A.; Mandal, T.; Padhi, M.M.; Dabur, R. Screening of some selected medicinal plants extracts for in-vitro antimicrobial activity. Middle-East J. Sci. Res. 2009, 4, 271-278.

129. Pavithra, P.S.; Sreevidya, N.; Verma, R.S. Antibacterial and antioxidant activity of methanol extract of evolvulus nummularius. Indian J. Pharmacol. 2009, 41, 233-236. [PubMed]

130. Patra, A.; Jha, S.; Murthy, P.N.; Vaibhav, A.D.; Chattopadhyay, P.; Panigrahi, G.; Roy, D. Anti-inflammatory and antipyretic activities of hygrophila spinosa t. Anders leaves (acanthaceae). Trop. J. Pharm. Res. 2009, 8, 133-137. [CrossRef]

131. Akroum, S. Antimicrobial activity of some alimentary and medicinal plants. Afr. J. Microbiol. Res. 2012, 6, 1860-1864.

132. Bajpai, V.K.; Rahman, A.; Shukla, S.; Mehta, A.; Shukla, S.; Arafat, S.M.Y.; Rahman, M.M.; Ferdousi, Z. Antibacterial activity of leaf extracts of pongamia pinnata from india. Pharm. Biol. 2009, 47, 1162-1167. [CrossRef] 
133. Bansal, S. Anti-bacterial efficacy of some plants used in folkaric medicines in arid zone. J. Pharm. Res. 2010, 3, 2640-2642.

134. Vinothkumar, P.S.K.; Ahmed, P.; Sivamani, K.; Senthilkumar, B. Evaluation of antibacterial activities of andrographis paniculata leaf extract against gram positive and gram negative species by in vitro methods. J. Pharm. Res. 2010, 3, 1513-1515.

135. Kumar, K.H.; Hullatti, K.K.; Sharanappa, P.; Sharma, P. Computative antimicrobial activity and tlcbioautographic analysis of root and aerial parts of andrographis serpyllifolia. Int. J. Pharm. Pharm. Sci. 2010, 2, 52-54.

136. Jamuna, B.A.; Rai, V.R.; Samaga, P.V. Evaluation of the antimicrobial activity of three medicinal plants of south india. Malays. J. Microbiol. 2011, 7, 14-18. [CrossRef]

137. Khanahmadi, M.; Rezazadeh, S.; Taran, M. In vitro antimicrobial and antioxidant properties of smyrnum cordifolium Boiss. (Umbelliferae) extract. Asian J. Plant Sci. 2010, 9, 99-103.

138. Koperuncholan, M.; Kumar, P.S.; Sathiyanarayanan, G.; Vivek, G. Phytochemical screening and antimicrobial studies of some ethnomedicinal plants in south-eastern slope of western ghats. Int. J. Med. Res. 2010, $1,48-58$.

139. Niranjan, M.H.; Kavitha, H.U.; Sreedharamurthy, S.; Sudarshana, M.S. Antibacterial activity of schrebera swietenioides roxb. Against some human pathogenic bacteria. J. Pharm. Res. 2010, 3, 1779-1781.

140. Naveen, S.M.T. Evaluation of antibacterial activity of flower extracts of cassia auriculata. Ethnobot. Leafl. 2010, 14, 8-20.

(C) 2017 by the authors. Licensee MDPI, Basel, Switzerland. This article is an open access article distributed under the terms and conditions of the Creative Commons Attribution (CC BY) license (http://creativecommons.org/licenses/by/4.0/). 